\title{
Using a Media-Article Approach to Quantitative Reasoning as an Honors Course: An Exploratory Study
}

Stuart Boersma

Central Washington University, boersmas@cwu.edu

Dominic Klyve

Central Washington University, klyved@cwu.edu

Follow this and additional works at: https://digitalcommons.usf.edu/numeracy

Part of the Mathematics Commons

\section{Recommended Citation}

Boersma, Stuart, and Dominic Klyve. "Using a Media-Article Approach to Quantitative Reasoning as an Honors Course: An Exploratory Study." Numeracy 6, Iss. 1 (2013): Article 5. DOI: http://dx.doi.org/ 10.5038/1936-4660.6.1.5 


\title{
Using a Media-Article Approach to Quantitative Reasoning as an Honors Course: An Exploratory Study
}

\author{
Abstract \\ In this study, we investigate student performance on a basic skills assessment of percentages and ratios \\ in two cohorts of students: the general (non-STEM) student body (cohort G) and (non-STEM) honors \\ students (cohort $\mathrm{H}$ ). Both cohorts used a media-article approach to the study of quantitative reasoning. A \\ pre- and a post-intervention assessment were administered with a two-week intervention period \\ consisting of critical analyses of the use of percentages and ratios in media articles. Using non- \\ parametric techniques, no statistically significant improvement was measured in cohort $\mathrm{G}$ while cohort $\mathrm{H}$ \\ students showed statistically significant improvement on several items.

\section{Keywords} \\ quantitative reasoning, assessment, honors students, high-achieveing students

\section{Creative Commons License} \\ cc) (i) (8) \\ This work is licensed under a Creative Commons Attribution-Noncommercial 4.0 License

\section{Cover Page Footnote} \\ Stuart Boersma is a Professor of Mathematics at Central Washington University. He enjoys writing \\ expository mathematics papers and received the 2005 Trevor Evans Award from the Mathematical \\ Association of America. \\ Dominic Klyve is a an Assistant Professor of Mathematics at Central Washington University. In addition to \\ his interest in effectively teaching quantitative literacy, he is interested in eighteenth century mathematics \\ and computational number theory.
}




\section{Introduction}

In the first issue of Numeracy, Scheaffer (2008) proposed guidelines for building a research knowledge base for quantitative literacy (QL). Based on the report Using Statistics Effectively in Mathematics Education Research (American Statistical Association 2007), he identified five main components of a research program and provided a graphical model of how these components interact and influence one another (Fig. 1).

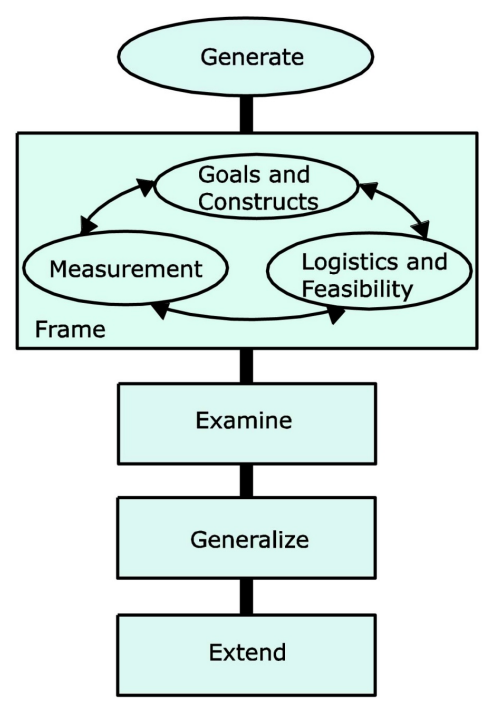

Figure 1. Structure and components of a research program (Scheaffer, 2008, Fig. 1).
As educators dedicated to improving the QL experience of students at our institution, we hope that we can contribute to the growing knowledge base of research in QL by conducting small-scale studies as opportunities present themselves as we teach. This paper will describe one such study in which we had the opportunity to compare success in a narrow area of QL between two very different cohorts of students in two very similar QL classes. While this study was necessarily constrained by a variety of parameters typically encountered by full-time teachers (e.g., inability to randomize), we hope that our preliminary results will enable future researchers to better frame their questions as they begin to examine other similar studies and design larger-scale studies to extend and generalize to larger populations.

Being familiar with Madison et al.'s (2009 [2012]) approach to teaching quantitative literacy within the context of case studies of media articles, we felt that that approach would lend itself well to the higher-achieving students within our university's honors college. We did not wish to compare Madison et al.'s approach to QL with other textbooks but, rather, compare this particular approach to two different cohorts of students. Our underlying question of interest was "Do students need a basic skill set before they can learn quantitative literacy in a context-rich environment?"

Central Washington University's "quantitative reasoning" course is titled "Math 101: Math in the Modern World." All students at CWU must receive credit in either this course or a higher-level mathematics course such as pre-calculus or calculus in order to graduate. Thus, Math 101 is typically populated only by non- 
STEM majors and is probably quite similar to other so-called "Math for Liberal Arts Majors" courses. The Mathematics Department offers approximately 26 sections of this course every academic year, and most instructors use Bennett and Briggs (2011).

Recently, some instructors of Math 101 began using Madison et al. (2009 [2012]). This text uses complete media articles and collections of study questions to provide students with authentic contextual settings that involve quantitative reasoning. While the quantitative skills necessary for success in this course are relatively elementary (e.g., working with percentages, ratios, and proportions; exploring linear and exponential growth; reading graphical displays of data), the increased demand for careful critical reading and writing makes this a challenging course for many of our students. Watson (2004), Dingman and Madison (2010), Madison and Dingman (2010) and Boersma et al. (2011) also point out that newspaper articles can be a rich source of contextually rich and quantitatively demanding material and provide further details on designing and assessing such courses.

Recently we began offering Math 101, using Madison et al. (2009 [2012]), to students enrolled in CWU's Douglas Honors College. We wanted to take this opportunity to compare student performance and learning between two different cohorts of students: general non-STEM majors and higher-achieving non-STEM

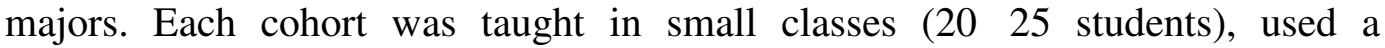
contextually rich and demanding approach to $\mathrm{QR}$, and was assessed using very similar instruments. We present the results of our analysis of a single assessment instrument composed of short-answer questions involving percentages and ratios.

\section{A Tale of Two Cohorts}

\section{Cohort G: The general student body}

Central Washington University is a public institution with about 10,000 (fulltime-equivalent) students. It grants bachelor's and master's degrees, and serves primarily the Pacific Northwest. CWU is not particularly selective; it accepts $78 \%$ of all applicants, and has developmental programs in Mathematics and English available for degree-seeking students who lack adequate preparation.

Our study considers students taken from this general population in a Math 101 class. Though traditionally taught in classes of size 45, the class constituting Cohort G consisted of 23 students from Fall 2009. This class was taught by one of us (SB) and used the textbook Madison et al. (2009 [2012]).

We did not collect specific demographic information from the students of Cohort G. We have no reason to believe that those students were not representative of the general population, background data for which are summarized in Table 1. Students are placed into Math 101 at CWU by SAT-M 
(500 or above), ACT-M (19 or above) COMPASS-Pre-algebra (50 or above), COMPASS-Algebra (26 or above).

\section{Cohort H: The Douglas Honors College}

The Douglas Honors College (DHC) is a small honors program within Central Washington University. This "school-within-a-school" is not itself degreegranting, although students can earn a major in the DHC. At the beginning of 2011, there were 173 students enrolled out of almost 10,000 at CWU; DHC students thus represent about $2 \%$ of the student body. These students do not necessarily represent the "top" $2 \%$ under any particular measure, however. In order to be part of the DHC, a student has to voluntarily choose to apply to the program. Acceptance criteria are based primarily on high school grades and standardized test scores (primarily SAT and ACT).

On average, students in the honors college have considerably better college preparation. In fact, for most measures of college preparation, the $25^{\text {th }}$ percentile of DHC students corresponded to the $75^{\text {th }}$ percentile of the general college population (see Table 1). In our experience, the stronger background went beyond just test scores. On average, the students in the honors college had more

Table 1

High School Performance Data for the Study's Two Cohorts

\begin{tabular}{lll}
\hline & Cohort G & Cohort H \\
$\begin{array}{l}\text { SAT 25 } \\
\text { percentile* }\end{array}$ & $890-1120$ & $1090-1210$ \\
$\begin{array}{l}\text { ACT } 25^{\text {th }}-75^{\text {th }} \\
\text { percentile }\end{array}$ & $18-24$ & $25-29$ \\
$\begin{array}{l}\text { HS GPA 25 } \\
\text { percentile }\end{array}$ & & $3.47-3.80$ \\
\hline
\end{tabular}

* SAT scores include math and verbal scores only. general knowledge, more interest in the world around them, and had stronger student skills. Our observations suggest that they complete assignments on time, study for tests, and attend class more regularly than do students from the general population. Cohort $\mathrm{H}$ consisted of non-STEM majors enrolled in the DHC, were taught in two small classes by the authors (twenty students in each) in Fall 2011, and used the textbook Madison et al. (2009 [2012]).

\section{Description of Assessment}

Our study focuses on one assessment of a fairly narrow set of skills - questions involving percentages and ratios. An understanding of percentages can serve as a litmus test for a quantitative reasoning course. Percentages arise from inherently real-world problems (we encounter percentages every day); they are taught from an early age; they involve no mathematics beyond the level of basic algebra; and they play an important role in the way information is conveyed in today's society. 
The assessment instrument is in Appendix 1. It consisted of eight items categorized, roughly, as follows:

Item 1: Numerical Reasoning: Recognizing that large percentages of smaller populations may be smaller than small percentages of large populations.

Item 2: Proportional Reasoning: Using percentages to rescale a statement about a population to a statement about a sample.

Item 3: Proportional Reasoning: The habit of mind to perform "per capita" calculations for the sake of comparisons.

Item 4: Language of Change: Correctly using percentages and ratios to compare two quantities.

Item 5: [omitted from study due to an error on the post-classwork assessment]

Item 6: Algebraic Reasoning: Finding the starting value of a quantity given the final value and the percent change.

Items 7-8: Language of Change: Recognizing absolute and relative changes in rates.

\section{Methods}

The assessment instrument in Appendix 1 was given to each Math 101 class in the study during the first week of class. The students were told that it was an initial assessment tool. Because it tested material not yet taught in the course, students' scores did not count toward their final grade. However, students did receive homework credit for attending class and taking the quiz. Additionally, as an added incentive to take the assessment seriously, extra credit was promised for students who scored very well. Instructors handed back the graded assessments shortly after the students took them, so students knew which items they got correct and which they missed. Students were encouraged to seek help outside of the class if they did not understand how to obtain the correct answer.

Each of the three sections of the class in this study was taught with the same classroom practice. For the section on percentages and ratios, each class covered case studies 2.1 (an examination of letters to the editor discussing income tax rates), 2.3 (an investigation into the overcharging of a city's water/sewer customers based on incorrect interpretations of percent reductions), and 2.5 (a detailed study of the confusing elements of the English language when describing portions of populations) from the Madison et al. casebook. Students were given the assignment of reading a newspaper article from the book outside of class; 
often there were some basic computation homework questions assigned as well. When we met in class the next day, students were given a chance to ask questions or discuss the article as a class.

Students were then organized into small groups to work on the case study questions from the section. These are more-challenging, content-rich questions which often involve writing or creative problem solving. While the students worked on these questions, the instructor would circulate around the room, monitoring and helping individual groups.

After about a half-hour, the groups would come together, and they would again discuss answers as a class. Typically this involved several groups writing their solutions or ideas on the board. At the end of class, homework, usually in the form of computational practice, was sometimes assigned.

A second (post-classwork) assessment was given approximately three weeks into class and graded as a quiz; students knew it would be another test of their knowledge of percentages, but they were not told how closely the graded quiz would parallel the pre-classwork assessment. While this quiz featured items identical and/or similar to those in the first assessment, it also contained additional questions based on the material that had been studied to date. Our study focuses only on those items which appear on both the pre- and post-classwork assessments. While the items appeared in a different order on the post-classwork assessment, Appendix 2 contains the actual items arranged in order to make it easy to compare the pre- and post-classwork versions of each item.

For each of the assessments (pre- and post-), student responses were graded on a simple binary (incorrect / correct) scale.

For each of the seven items on the assessment instrument, we can ask three questions:

Did the students in Cohort G show (statistically significant) improvement of their understanding of the concept or skill tested by this problem?

Did the students in Cohort H show improvement?

Was there a significant difference in the change in understanding between the two cohorts of students?

We considered answering the first two questions using a standard matched pairs $t$-test. Though a reasonable option, the matched-pairs $t$-test assumes that the underlying distribution is (roughly) normally distributed, and is not an ideal choice for binary data. Instead, we employed McNemar's Test. First introduced in 1947, McNemar's Test functions like a matched-pairs $t$-test. That is, for binary (dichotomous) data, McNemar's Test tests the null hypothesis "the proportion of students answering a question correctly on the pre-classwork test is the same as 
the proportion answering the question correctly on the post-classwork test," assuming that the data are matched (i.e., we match each individual's two tests).

In order to answer the third question, we needed to classify the possible outcomes of pre- and post-classwork testing for each of the questions. Because a student's answer on each test is a binary variable ( 0 for incorrect, 1 for correct), there are four possible outcomes. We ranked these as follows:

\begin{tabular}{|c|c|c|c|}
\hline Pre- & $\underline{\text { Post- }}$ & $\underline{\text { Rank }}$ & $\underline{\text { Justification }}$ \\
\hline 1 & 0 & -1 & instruction harmed understanding \\
\hline 0 & 0 & $\mathbf{0}$ & instruction made no difference \\
\hline 1 & 1 & 1 & $\begin{array}{l}\text { student already understood material; } \\
\text { instruction didn't negate this }\end{array}$ \\
\hline 0 & 1 & 2 & $\begin{array}{l}\text { ideal outcome; student learned material in } \\
\text { course. }\end{array}$ \\
\hline
\end{tabular}

Ranks of the student in the two classes were compared via the Mann-Whitney $\mathrm{U}$ test (essentially the same as the Wilcoxon Rank-Sum test). The $p$-values refer to the null hypothesis that the distribution of values is the same for each of the two cohorts.

\section{Results}

The results for each question are listed in Table 2 and displayed in Figure 2.

Table 2.

Percentage of class getting each question right

\begin{tabular}{ccccc}
\hline \multirow{2}{*}{ Question } & \multicolumn{2}{c}{ Cohort G } & \multicolumn{2}{c}{ Cohort H } \\
& Pre & Post & Pre & Post \\
\hline $\mathbf{1}$ & $55 \%$ & $60 \%$ & $36 \%$ & $75 \%$ \\
$\mathbf{2}$ & $85 \%$ & $75 \%$ & $83 \%$ & $92 \%$ \\
$\mathbf{3}$ & $55 \%$ & $65 \%$ & $92 \%$ & $92 \%$ \\
$\mathbf{4}$ & $55 \%$ & $55 \%$ & $56 \%$ & $69 \%$ \\
$\mathbf{6}$ & $10 \%$ & $25 \%$ & $39 \%$ & $81 \%$ \\
$\mathbf{7}$ & $90 \%$ & $80 \%$ & $83 \%$ & $92 \%$ \\
$\mathbf{8}$ & $20 \%$ & $35 \%$ & $56 \%$ & $78 \%$ \\
\hline
\end{tabular}



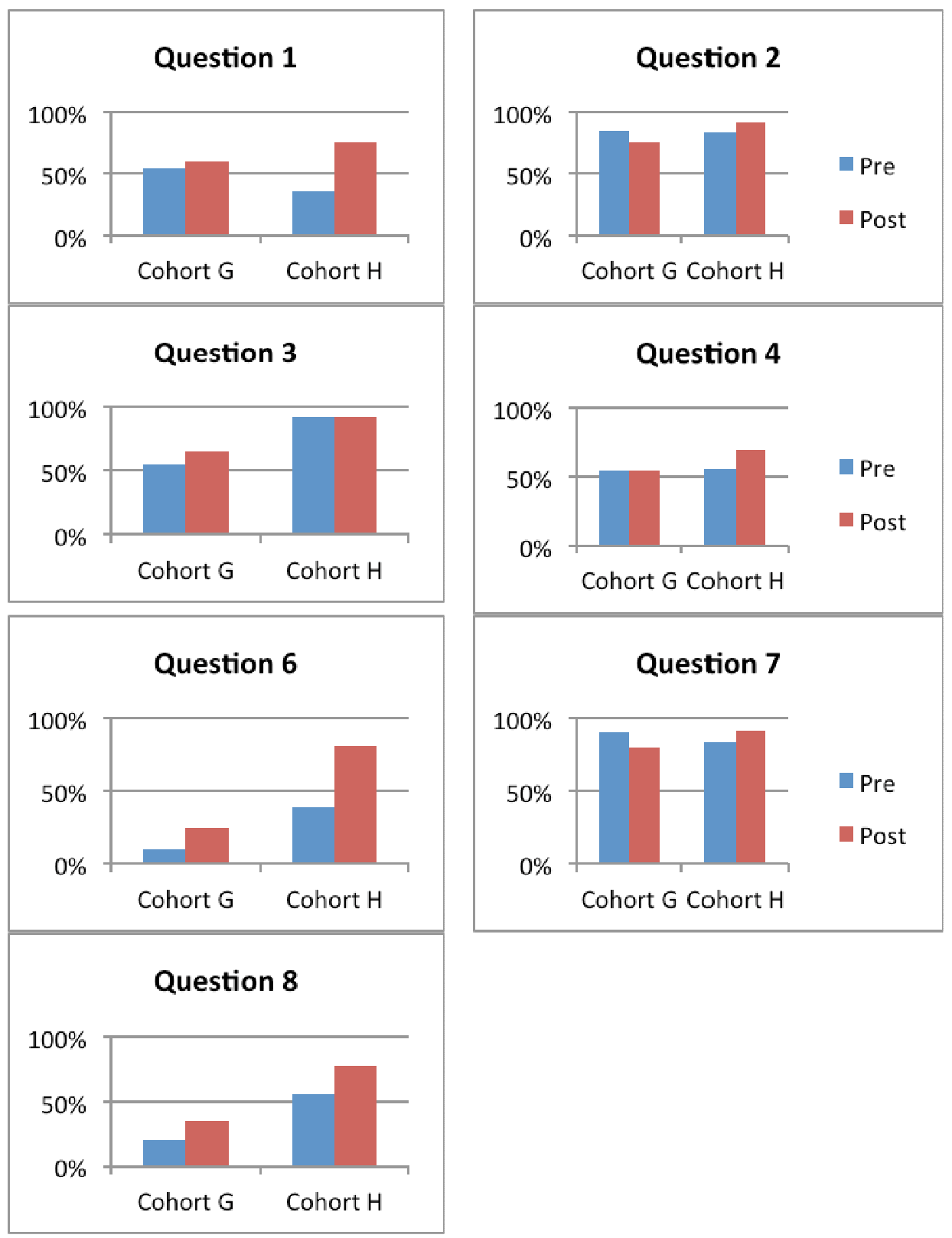

Figure 2. Percentage of students getting the question correct by question and by test (preand post-).

Table 3 gives (two-tailed) $p$-values for improvement for each of these questions. The data include all students who completed both assessments. Note that for two of the questions, the percentage of cohort $G$ students answering correctly actually dropped; in neither case was the decline significant. 
Although it seems that the honors students composing Cohort $\mathrm{H}$ responded better to instruction, the difference was not significant for most individual questions. However, the difference may be quite a bit greater than what appears here. After all, the students in Cohort $\mathrm{H}$ started with higher overall scores, and we might expect that it would be more difficult to

Table 3.

$p$ Values for Significance Tests of Improvements in Scores

Question $\begin{gathered}\text { Improvement } \\ \text { in Cohort G }\end{gathered} \quad \begin{gathered}\text { Improvement } \\ \text { in Cohort } H\end{gathered} \quad \begin{gathered}\text { Classrooms are } \\ \text { significantly }\end{gathered}$

Question in Cohort $\mathbf{G}$ in Cohort $\mathbf{H}$ significantly

\begin{tabular}{cccc} 
& $(\boldsymbol{N}=\mathbf{2 0})$ & $(\boldsymbol{N}=\mathbf{3 6})$ & different \\
1 & 1 & $<.001^{* *}$ & .054 \\
2 & .625 & .453 & .070 \\
3 & .625 & 1 & .221 \\
4 & 1 & .267 & .319 \\
6 & .25 & $<.001^{* *}$ & $.001^{* *}$ \\
7 & .625 & .508 & .104 \\
8 & .25 & $.021^{*}$ & $.012^{*}$ \\
\hline$* p<0.05$ (significant) & &
\end{tabular}

$* * p<0.01$ (very significant) raise their scores.

We therefore ask a related question of those students who missed a particular problem in the pre-classwork test. What percentage of them got the question correct in the post-classwork test? Results from this question are in Table 4.

Table 4.

Proportion of Those Students From Each Cohort Who Initially Missed the Problem Who Improved.

\begin{tabular}{ccccc}
\hline & \multicolumn{2}{c}{ Cohort G } & \multicolumn{2}{c}{$\begin{array}{c}\text { Cohort H } \\
\text { Percentage } \\
\text { Improved }\end{array}$} \\
\hline $\mathbf{1}$ & 9 & $33.3 \%$ & 23 & $60.9 \%$ \\
$\mathbf{2}$ & 3 & $33.3 \%$ & 6 & $83.3 \%$ \\
$\mathbf{3}$ & 9 & $33.3 \%$ & 3 & $100.0 \%$ \\
$\mathbf{4}$ & 9 & $44.4 \%$ & 16 & $56.3 \%$ \\
$\mathbf{5}$ & 8 & $25.0 \%$ & 4 & $25.0 \%$ \\
$\mathbf{6}$ & 17 & $11.8 \%$ & 22 & $72.7 \%$ \\
$\mathbf{7}$ & 2 & $50.0 \%$ & 6 & $100.0 \%$ \\
$\mathbf{8}$ & 16 & $18.8 \%$ & 16 & $56.3 \%$ \\
\hline
\end{tabular}

* $N$ is the number of students from each cohort who missed the problem on the first assessment.
As can be seen in Table 4, the proportion of Cohort $\mathrm{H}$ students who improved was higher (sometimes significantly higher) on every question than the comparable proportion of Cohort G students. Even more striking, on the four assessment items which did not show statistically significant improvement (Questions 2, 3, 4, and 7 from cohort $\mathrm{H}$ ), the percentages of students who scored zero on the pre-classwork assessment and one on the postclasswork assessment were $83.3 \%$, $100 \%, \quad 56.3 \%$, and $100 \%$ respectively.

\section{Discussion}

The most disheartening conclusion concerns the analysis of Cohort G's performance on this assessment instrument. For these students, there was no statistically significant improvement on any assessment item! There are several factors which may have favored these results. First, while quantitative data were not collected for this study, it appeared (anecdotally anyway) that students in 
Cohort $\mathrm{G}$ rarely took the time to ask the instructor questions outside of class. Second, elementary concepts and skills involving percentages and ratios may not be easily mastered simply by studying contextually rich problems (a la Madison et al.). Third, it is reasonable to conjecture that students' prior knowledge and misconceptions about percentages are so ingrained in their habits of thinking that most direct instruction has little to no effect. This conjecture could be tested by repeating the study but changing the two weeks of intervention to include a component which requires students to carefully identify their misconceptions, directly acknowledging the correct interpretation, and continually practice similar calculations and interpretations.

Conversely, analysis of Cohort H's performance on this assessment instrument allows one to make positive claims related to student learning. Cohort $\mathrm{H}$ students improved, or stayed the same, on all seven assessment items. On three of the seven items this improvement is indeed statistically significant. Importantly, as was pointed out earlier, the relatively high percentage of students receiving a correct score on pre-classwork assessment items 2, 3, and 7 is the most likely culprit for high $p$-values. As Table 4 shows, when Cohort $\mathrm{H}$ students had the room to improve, they often did. Similar conjectures may be made that would support these data. First, Cohort $\mathrm{H}$ students were more proactive in seeking out instructor help. Second, the direct-instruction phase of the intervention period was more conducive for student learning in Cohort $\mathrm{H}$ students, as compared with Cohort G students. Without further study one cannot safely conjecture about the role of prior knowledge or misconceptions for these students. It could very well be that direct instruction simply provided these students with enough practice to "remind" them how to work correctly with percentages and change their behavior in a positive way. Teaching these ideas and skills embedded in contextually rich problems seems to work for these students.

\section{Conclusion}

While it has already been acknowledged that teaching $\mathrm{QR}$ is difficult and demanding, this study suggests another troubling conundrum. While QR often involves elementary mathematics, it is often the emphasis one places on critical reading, writing, and analysis which helps identify a QR course as a college-level mathematics course. However, this preliminary study shows that students who lack a certain basic level of understanding of percentages and ratios and, quite possibly, also lack a certain level of critical reading and study skills, may not be able to overcome these deficiencies in a fast-paced demanding course without some form of supplemental instruction or remedial reinforcements. Because we believe that a majority of the students enrolled in college-level QR courses across the country may be similar to those in Cohort $G$, this study suggests that 
instructors must be prepared to improve student study habits along with their mathematical skills in order for students to be successful in demonstrating quantitative literacy skills in authentic contextual situations.

\section{Acknowledgments}

We would like to thank the reviewers and editors for their thoughtful suggestions which led to a much improved paper.

\section{References}

American Statistical Association. 2007. Using Statistics Effectively in Mathematics Education Research. Working Group of Statistics in Mathematics Education Research, R. Scheaffer, Chair. http://www.amstat.org/education/pdfs/UsingStatisticsEffectivelyinMathEdRe search.pdf .

Bennett, J., and W. Briggs. 2011. Using and Understanding Mathematics: A Quantitative Reasoning Approach. $5^{\text {th }}$ ed. Boston: Addison Wesley.

Boersma, S., C. Diefenderfer, S. Dingman, and B. Madison. 2011. Quantitative Reasoning in the Contemporary World, 3: Assessing Student Learning.

Numeracy 4 (2). http://dx.doi.org/10.5038/1936-4660.4.2.8

Dingman, S. and B. Madison. 2010. Quantitative Reasoning in the Contemporary World, 1: The Course and Its Challenges. Numeracy 3 (2). http://dx.doi.org/10.5038/1936-4660.3.2.4

Madison, B., S. Boersma, C. Diefenderfer, and S. Dingman. 2009 [2012]. Case Studies for Quantitative Reasoning: A Casebook of Media Articles, $2^{\text {nd }}$ ed. $\left[3^{\text {rd }}\right.$ ed.] New York: Pearson Custom Publishing.

Madison, B. and S. Dingman. 2010. Quantitative Reasoning in the Contemporary World, 2: Focus Questions for the Numeracy Community. Numeracy 3 (2). http://dx.doi.org/10.5038/1936-4660.3.2.5

Scheaffer, R.L. 2008. Scientifically Based Research in Quantitative Literacy: Guidelines for Building a Knowledge Base. Numeracy 1 (1). http://dx.doi.org/10.5038/1936-4660.1.1.3

Watson, J. 2004. Quantitative Literacy in the Media: An Arena for Problem Solving. The Australian Mathematics Teacher 60, Part 1, 34-40. 


\section{Appendix A}

\section{Pre-Intervention Assessment}

(For questions 1 and 2) China has 1.06 males for every female and the United States has 0.97 males for every female. Furthermore, assume that approximately $10 \%$ of all women in China smoke, whereas about $19 \%$ of all women in the United States smoke.

1. Which is greater, the number of women in China who smoke or the number of women in the United States who smoke?

2. If you choose 100 Chinese women at random and 100 American women at random, in which group would you expect there to be more smokers?

3. India (with a population of nearly 1.2 billion) consumes approximately 265 million tons of coal each year, whereas Germany (with a population of 82 million) only consumes about 239 million tons each year. Is it fair to say that Germans are more frugal with their use of coal then Indians? Explain your reasoning.

4. John pays $\$ 50$ for a calculator and Tina pays $\$ 70$ for a calculator. Which of the following statements correctly compares Tina's cost to John's cost? Circle any correct statement

Tina's cost is $20 \%$ more than John's cost.

John's cost is $40 \%$ less than Tina's cost.

Tina's cost is 1.2 times John's cost.

John's cost is $20 \%$ less than Tina's cost.

Tina's cost is 1.4 times John's cost.

5. A $\$ 45$ pair of jeans is on the " $75 \%$ off rack" at the mall. How much is the sale price?

6. How much do you have to charge for an item if you want the price plus the tax of $8 \%$ to come out to $\$ 35$ ?

(For questions 7 and 8) In 2000, the national unemployment rate was 4 percent.

7. If the unemployment rate increased by 6 percent, what would be the new unemployment rate?

8. Is there another reasonable way to interpret "an increase of 6 percent" that would lead to a different answer? If so, provide the new unemployment rate and a brief explanation of your reasoning. 


\title{
Appendix B
}

\section{Post-Intervention Assessment}

\author{
(appeared in a different order when given to students)
}

(For questions 1 and 2) China has 1.06 males for every female and the United States has 0.97 males for every female. Furthermore, assume that approximately $10 \%$ of all women in China smoke, whereas about $19 \%$ of all women in the United States smoke.

1. Which is greater, the number of women in China who smoke or the number of women in the United States who smoke?

2. If you choose 100 Chinese women at random and 100 American women at random, in which group would you expect there to be more smokers?

3. India (with a population of nearly 1.2 billion) consumes approximately 265 million tons of coal each year, whereas Germany (with a population of 82 million) only consumes about 239 million tons each year. Is it fair to say that Germans are more frugal with their use of coal then Indians? Explain your reasoning.

4. Jeremiah bought a new video game for $\$ 70$ while Alex bought the same game for $\$ 50$. Which of the following statements correctly compares Alex's cost to Jeremiah's cost? Circle any correct statement.

a. Jeremiah's cost is $20 \%$ more than Alex's cost.

b. Alex's cost is $40 \%$ less than Jeremiah's cost.

c. Jeremiah's cost is 1.2 times Alex's cost.

d. Alex's cost is $20 \%$ less than Jeremiah's cost.

e. Jeremiah's cost is 1.4 times Alex's cost.

5. The price of milk fell $4 \%$ over the last three months to $\$ 2.25$ a gallon. What was the price of milk three months ago?

6. If the price of some books together with $8 \%$ sales tax came to $\$ 125$, how much were the books before the tax was added?

(For questions 7 and 8) In 2000, the national unemployment rate was 4 percent.

7. If the unemployment rate increased by 6 percent, what would be the new unemployment rate?

8. Is there another reasonable way to interpret "an increase of 6 percent" that would lead to a different answer? If so, provide the new unemployment rate and a brief explanation of your reasoning. 